\title{
BMJ Open Prevalence of diabetes and pre-diabetes in Bangladesh: a systematic review and meta-analysis
}

\author{
Sohail Akhtar (10 , ${ }^{1}$ Jamal Abdul Nasir, ${ }^{1}$ Aqsa Sarwar, ${ }^{1}$ Nida Nasr, ${ }^{1}$ Amara Javed, ${ }^{1,2}$ \\ Rizwana Majeed, ${ }^{1}$ Muhammad Abdus Salam, ${ }^{1}$ Baki Billah ${ }^{3}$
}

To cite: Akhtar S, Nasir JA, Sarwar A, et al. Prevalence of diabetes and pre-diabetes in Bangladesh: a systematic review and meta-analysis. BMJ Open 2020;10:e036086. doi:10.1136/ bmjopen-2019-036086

- Prepublication history and additional material for this paper are available online. To view these files, please visit the journal online (http://dx.doi. org/10.1136/bmjopen-2019036086).

Received 30 November 2019 Revised 02 June 2020 Accepted 24 July 2020
Check for updates

(C) Author(s) (or their employer(s)) 2020. Re-use permitted under CC BY-NC. No commercial re-use. See rights and permissions. Published by BMJ.

${ }^{1}$ Deaprtment of Statistics, Government College University Lahore, Lahore, Punjab, Pakistan ${ }^{2}$ School of Statistics, Minhaj University, Lahore, Pakistan ${ }^{3}$ SPHPM, Monash University, Melbourne, Victoria, Australia

Correspondence to

Dr Sohail Akhtar;

s.akhtar@gcu.edu.pk

\section{ABSTRACT}

Objective The purpose of this paper is to perform a systematic review and meta-analysis in order to summarise the prevalence of diabetes and pre-diabetes and their associated risk factors in Bangladesh.

Design Systematic review and meta-analysis.

Participants General population of Bangladesh. Data sources PubMed, Medline, Embase, Bangladesh Journals Online, Science Direct, Scopus, Cochrane Library and Web of Science were used to search for studies, published between 1st of January 1995 and 31st of August 2019 , on the prevalence of diabetes and pre-diabetes and their associated risk factors in Bangladesh. Only articles published in the English language articles were considered. Two authors independently selected studies. The quality of the articles was also assessed.

Results Out of 996 potentially relevant studies, 26 population-based studies, which together involved a total of 80775 individuals, were included in the metaanalysis. The pooled prevalence of diabetes in the general population was $7.8 \%$ (95\% Cl: 6.4-9.3). In a sample of 56452 individuals, the pooled prevalence of pre-diabetes was $10.1 \%$ (95\% Cl: 6.7-14.0; 17 studies). The univariable meta-regression analyses showed that the prevalence of diabetes is associated with the factors: the year of study, age of patients and presence of hypertension. The prevalence of diabetes was significantly higher in urban areas compared with rural areas, while there was no significant gender difference.

Conclusions This meta-analysis suggests a relatively high prevalence of pre-diabetes and diabetes in Bangladesh, with a significant difference between rural and urban areas. The main factors of diabetes include urbanisation, increasing age, hypertension and time period. Further research is needed to identify strategies for early detecting, prevention and treatment of people with diabetes in the population.

PROSPERO registration number CRD42019148205.

\section{INTRODUCTION}

Diabetes is a major public health problem regionally and globally and is a leading cause of death in most countries. ${ }^{1}$ In 2019, the International Diabetes Federation estimated that 465 million $(9.3 \%)$ people worldwide had diabetes, and by 2045 , the number may rise to 700 million $(10.9 \%) .^{2}$ Similarly, the

\section{Strengths and limitations of this study}

- We used a comprehensive search strategy to identify all eligible studies and attempted to increase the quality and comparability of the included studies.

- Strong and reliable methodological and statistical methods were used.

- No publication bias was found in our analysis, which demonstrates that we did not miss any potential studies.

- Our analyses possessed a significant proportion of quantifiable heterogeneity.

- The common risk factors of diabetes and prediabetes were not sufficiently reported in many of the included studies.

prevalence of pre-diabetes in adults was estimated to be 374 million ( $7.5 \%$ ) people in 2019 and is predicted to increase to 548 million $(8.6 \%)$ by 2045 . The average life expectancy of patients with type 2 diabetes mellitus (T2DM) decreases by approximately 10 years, and $80 \%$ of patients with T2DM die from cardiovascular complications. ${ }^{3}$ Furthermore, it was projected that between 2010 and 2030, there will be $69 \%$ more adults with diabetes in developing countries and $20 \%$ more in developed countries. ${ }^{4}$ Around $79 \%$ of people with diabetes live in low-income or middleincome countries, and more than $60 \%$ live in Asian countries. ${ }^{3}$ A progressive increase in the prevalence of diabetes and pre-diabetes has been observed both in urban and rural areas in South Asia, which is mostly due to lifestyle changes and the transition to urbanisation and industrialisation. ${ }^{5-7}$ The rising rate of diabetes and its associated health complications threaten to reverse economic gains in developing countries. ${ }^{8}{ }^{9}$ Due to inadequate infrastructure for diabetes care, many developing countries will struggle to cope with this epidemic. $^{9}$

Bangladesh is a developing country and is facing a continuous growth in the prevalence 
of diabetes. According to the International Centre for Diarrhoeal Disease Research in Bangladesh in 2015, 7.1 million people had diabetes, 3.7 million cases were undiagnosed and about 129000 deaths were attributed to the disease. ${ }^{10}$ The prevalence of diabetes in Bangladesh, based on published studies, ranges from $2.21 \%$ to $35 \%{ }^{11}{ }^{12}$ However, the last meta-analysis was published in 2012, which converged studies published between 1995 and $2010 .^{13}$ Thus, a review is overdue to determine the prevalence of diabetes and pre-diabetes and their associated risk factors for the Bangladeshi population. The purpose of this systematic review and meta-analysis is to identify, select, summarise and estimate the pooled prevalence of diabetes and pre-diabetes and their associated risk factors in Bangladesh based on studies published between 1995 and 2019.

\section{METHODS}

\section{Design and registration}

This systematic review and meta-analysis followed the Preferred Reporting Items for Systematic Reviews and Meta-Analyses (PRISMA) guidelines. ${ }^{14}$

\section{Literature search}

A comprehensive literature search was conducted to identify studies, published between 1st of January 1995 and 31st of August 2019, on the prevalence of diabetes and pre-diabetes. Electronic searches were carried out systematically using the following databases: PubMed, Embase, Bangladesh Journals Online, Science Direct, Scopus, Cochrane Library and Web of Science. Using Medical Subject Headings, the following terms were searched for: 'type 2 diabetes', 'type-II diabetes', 'T2D', 'prevalence', 'impaired glucose tolerance', 'impaired fasting glucose', 'risk factors', 'risk factor', 'glucose intolerance', 'glucose abnormalities', 'Bangladeshi' and 'Bangladesh', as well as variations thereof. In addition, a snowball search method was used to search the reference lists of the included studies.

\section{Inclusion and exclusion criteria}

The inclusion criteria were as follows: the article (a) had sufficient data to estimate the prevalence of diabetes; (b) included a population-based or community-based survey and (c) was published in English. The exclusion criteria were as follows: the article (a) was irrelevant to diabetes; (b) was a review article; (c) was a case series or case report; (d) reported only on gestational diabetes; (e) was about a Bangladeshi community living outside of Bangladesh; (f) contained duplicate data (information) and $(\mathrm{g})$ contained data that were published in more than one article (the most up-to-date version was considered).

\section{Outcome measure}

A number of diagnostic methods and criteria were used to measure the diabetes and pre-diabetes in the included studies in this review. Fasting blood glucose (FBG $\geq 7.0$ or
$6.1)$, 2-hour oral glucose $(2 \mathrm{hFBG} \geq 11.1)$ and glycated haemoglobin $(\geq 6.5)$ were used individually or in combination of them as diabetes methods (criteria). Furthermore, 2hFBG, fasting plasma glucose (FPG), and FBG were considered individually or in combination of them as the diagnostic method of pre-diabetes and the diagnostic criteria were 2hFBG: 7.8-11.1, FPG: $6.1-6.9$ or 5.6-6.0 and FBG: 7.8-11.1.

\section{Data extraction}

The review of eligible articles identified by the searches was completed by the two investigators (AS and RM) to identify studies to be reviewed in full text. Each full-text study was then reviewed for eligibility by these investigators, and for each included study, data were extracted independently using Microsoft Excel V.2013. Any disagreement on extracted data was resolved by mutual consensus or consultation. The following data points were collected: first author, year of publication, year of data collection, geographical region (division or city) where the study was conducted, number of participants, percentage of male participants, mean age of participants, percentage of participants with hypertension, percentage of smoker participants, percentage of obese or overweight participants and participants' family history of diabetes.

\section{Methodological quality of the included studies}

The two investigators independently assessed the methodological quality of each included study using the Quality Assessment Tool for Observational Cohort and CrossSectional Studies. ${ }^{15}$ Any disagreement on the quality assessment checklist was resolved by discussion or consultation with a third investigator (MAS). We categorised the quality of each included study as good (for quality scores above $69 \%$ ), medium (for quality scores above $50 \%-69 \%$ ) and poor (for scores below 50\%).

\section{Statistical analyses}

All statistical analyses were performed using the software R V.3.6.1 (R Foundation for Statistical Computing, Vienna, Austria). Meta-analyses were performed with two packages: 'meta' and 'metafor'. We pooled the effect estimates, considering the DerSimonian-Laird inverse variance random-effects model, and presented the results in forest plots. ${ }^{16}$ Random-effects models are more conservative than fixed effects models and have better properties in the presence of heterogeneity, as random-effect models take into account both within-study and between-study variances. ${ }^{17-19}$ Freeman-Tukey double arcsine transformation was considered to stabilise the variance prior to the calculation of the pooled estimates. ${ }^{20}$ Heterogeneity was tested by using the $\chi^{2}$ test on Cochrane's $Q$ statistic, which was calculated by using $\mathrm{H}_{\text {and }} \mathrm{I}^{2}$ indices. The $\mathrm{I}^{2}$ index estimates the percentage of total variation across studies based on true between-study differences rather than on chance. Conventionally, $\mathrm{I}^{2}$ values of $0 \%-25 \%$ indicate low heterogeneity, $26 \%-75 \%$ indicate moderate heterogeneity and $76 \%-100 \%$ indicate substantial heterogeneity. ${ }^{21}$ 
We conducted subgroup analyses to find out the possible causes of substantial heterogeneity. Univariable metaregression was used to test for an effect of study and participants' characteristics by adding covariates. The covariates were geographical location, year of publication, sample size, year of data collection, gender, methodological quality and mean age of participants. We evaluated the symmetry of the funnel plots and considered the Egger's regression test to examine for publication bias, ${ }^{22} \mathrm{p}<0.10$ was considered to be statistically significant. Inter-rater agreement between the investigators, who were involved in study selection and data extraction, was assessed using Cohen's coefficient $(\kappa){ }^{23}$

\section{RESULT}

\section{Literature search}

We initially identified 996 potential articles. After elimination of duplicates, 514 articles remained. We screened the titles and abstracts, and excluded 326 irrelevant articles. Agreement between authors on abstract selection was high $(\kappa=0.896, p<0.001)$. We scrutinised the full texts of the remaining 53 papers for eligibility, 27 of which were excluded for the following reasons: nine studies did not mention the results of patients with diabetes, eight studies used the same datasets (which were duplicated for publication), three studies only assessed patients with type 1 diabetes and seven studies did not include enough information to estimate prevalence. Finally, only 26 studies met the inclusion criteria and data were extracted accordingly. The flow diagram of study selection is illustrated in figure 1; the PRISMA flow diagram ${ }^{14}$ and the PRISMA checklist are provided in the online supplemental file S1.

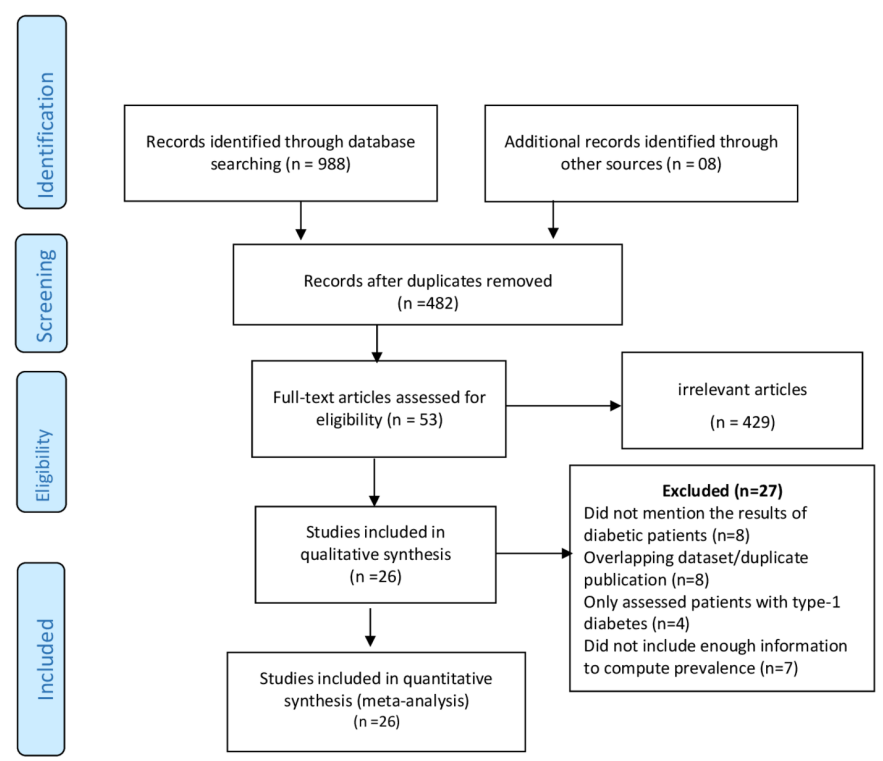

Figure 1 Flow diagram explaining the number of included and excluded articles in the meta-analysis on diabetes in Bangladesh, considered from the Preferred Reporting Items for Systematic Reviews and Meta-Analyses 2009 guideline.

\section{The characteristics of included studies}

Table 1 shows the main characteristics of the included studies. ${ }^{11}{ }^{12}{ }^{24-47}$ Nineteen out of the 26 studies used a cross-sectional research design, and 11 studies did not clearly specify a research design. The sample size of the included studies widely varied from $286^{44}$ to 12280 participants. ${ }^{46}$ The articles were published between January 1995 and February 2019, while the period of participant inclusion was from July $1994^{11}$ to March $2016{ }^{46}$ All divisions of Bangladesh were represented in the selected articles: 13 studies were conducted in Dhaka, ${ }^{11} 1224$ 29-32 34-36 $394^{43} 4_{2}$ studies in Khulna, ${ }^{40} 452$ studies in Mymensingh ${ }^{25} 27$ study in Ranpur, ${ }^{38} 1$ study in Chittagong, ${ }^{28} 1$ study in Barisal and Dhaka, ${ }^{40}$ and 3 studies at the national level. ${ }^{39} 4247$ Furthermore, 11 studies were conducted in rural areas, ${ }^{11} 262730-3235384045464$ in urban areas, ${ }^{12} 2433447$ studies in both settings ${ }^{25} 293941-4347$ and 1 study in a suburban area. ${ }^{34}$ The proportion of male participants ranged from $9 \%$ to $67 \%$ and the percentage of obese or overweight participants ranged from $5.7 \%$ to $47.2 \%$. The average age of participants ranged from 31.3 to 51.48 years. ${ }^{40}$ Twenty-three articles reported the gender of participants. After reviewing the quality of the studies, 16 were deemed to be of good quality, 10 of moderate quality and no article of poor quality. Agreement between authors on extracted data was high $(\kappa=0.87, \mathrm{p}<0.001)$.

\section{The prevalence of diabetes and pre-diabetes in Bangladesh}

The prevalence of diabetes is presented in table 2. The pooled prevalence of diabetes was $7.8 \%$ (95\% CI: 6.4-9.3, $\mathrm{I}^{2}=99.3 \%$, based on 26 articles) in a sample of 80775 participants. The graphical display of the pooled prevalence of diabetes is presented in the forest plot (see figure 2). The funnel plot (see figure 3) and the Egger regression test $(\mathrm{p}=0.84)$ showed no publication bias in the included study. The forest plot presented in figure 4 showed that the pooled prevalence of pre-diabetes was $10.1 \%$ (95\% CI: $6.7-14.0, \mathrm{I}^{2}=99.5 \%, \mathrm{n}=17$ ), which was estimated from a total of 56452 participants. The visual inspection of the funnel plot (see figure 5) showed no publication bias, which was confirmed by the Egger regression test $(\mathrm{p}=0.27)$.

\section{Heterogeneity and subgroup analysis}

The subgroup analysis is presented in table 2 . The prevalence of diabetes in male participants $(7.3 \%$; $95 \%$ CI: $5.5-9.4)$ was slightly higher than female participants (6.70\%; 95\% CI: 5.0-8.7), but the difference was insignificant. The prevalence of diabetes in urban populations (11.5\%; 95\% CI: 7.4-16.4) was significantly higher $(\mathrm{p}=0.0157)$ than rural populations $(6.2 \% ; 95 \% \mathrm{CI}$ : 4.6-7.9). The prevalence of diabetes in the age groups 20-30, 31-40, 41-50, and 50 and over were $2.8 \%(95 \%$ CI: $1.6-4.2), 6.5 \%$ (95\% CI: 3.1-11.1), 9.3\% (95\% CI: 4.7 -15.2 ) and $11.0 \%$ (95\% CI: 5.7-17.7), respectively. The highest prevalence was observed in the 50 and over age group, and the overall prevalence increased with age. 

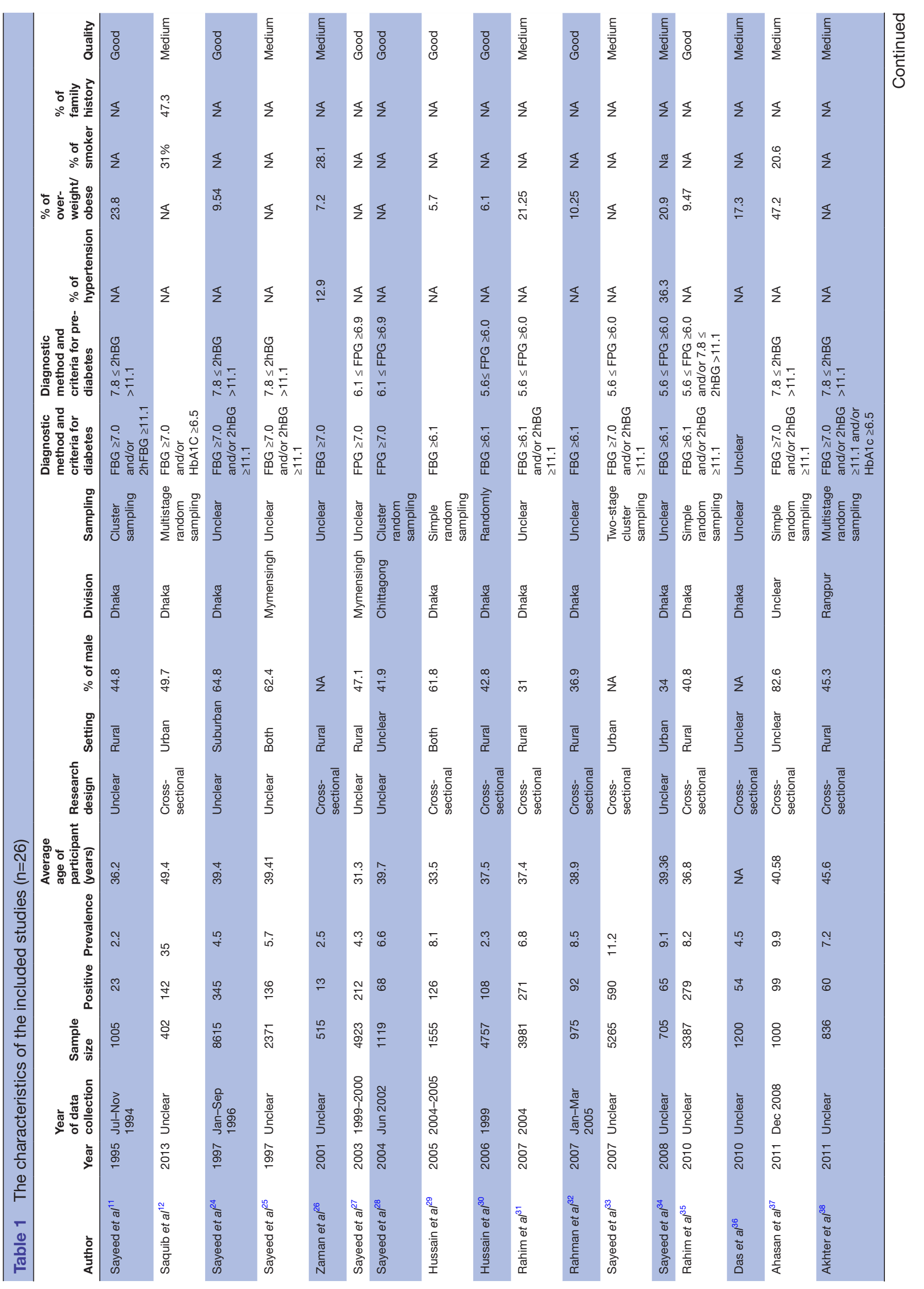

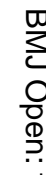




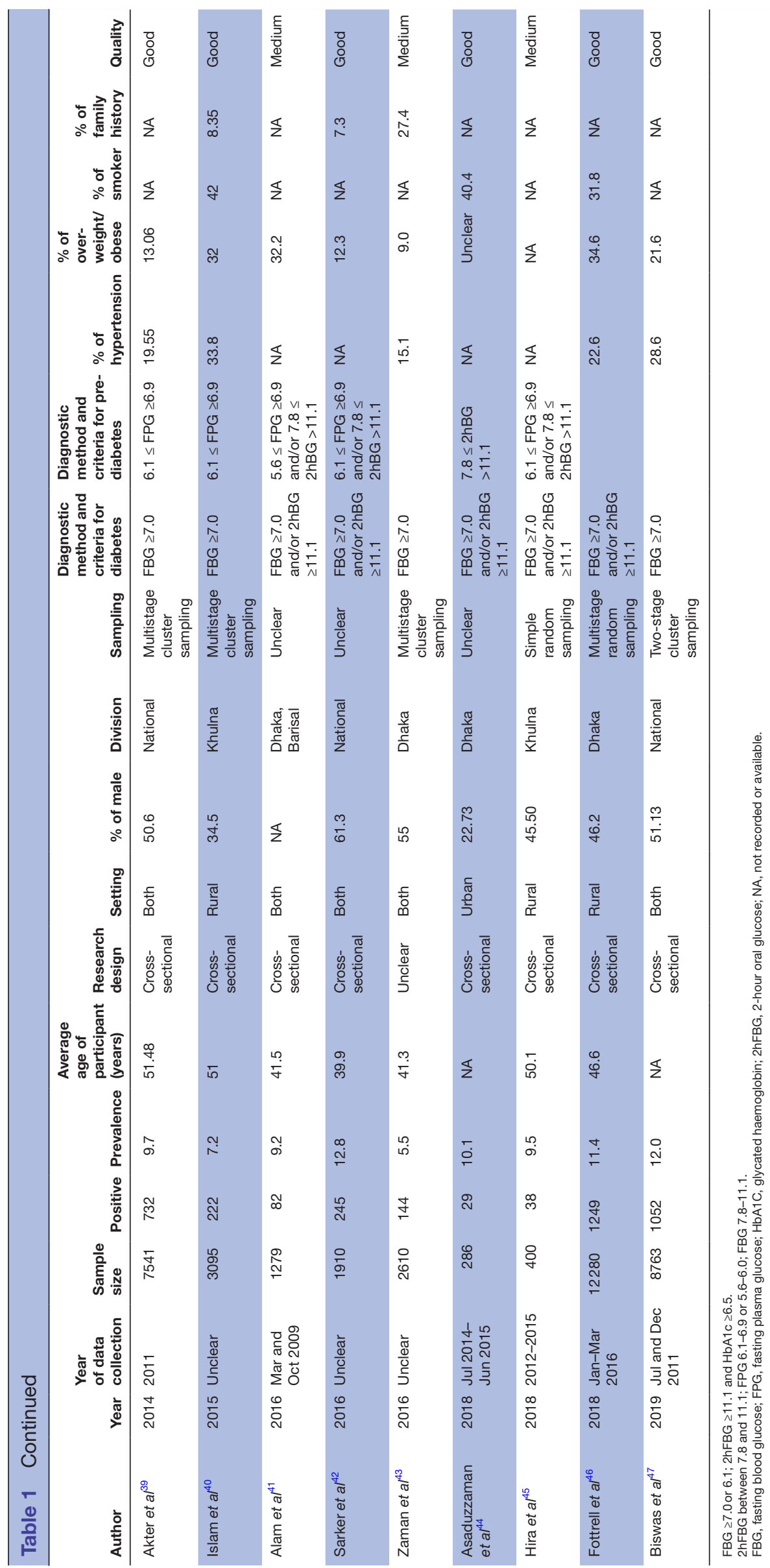




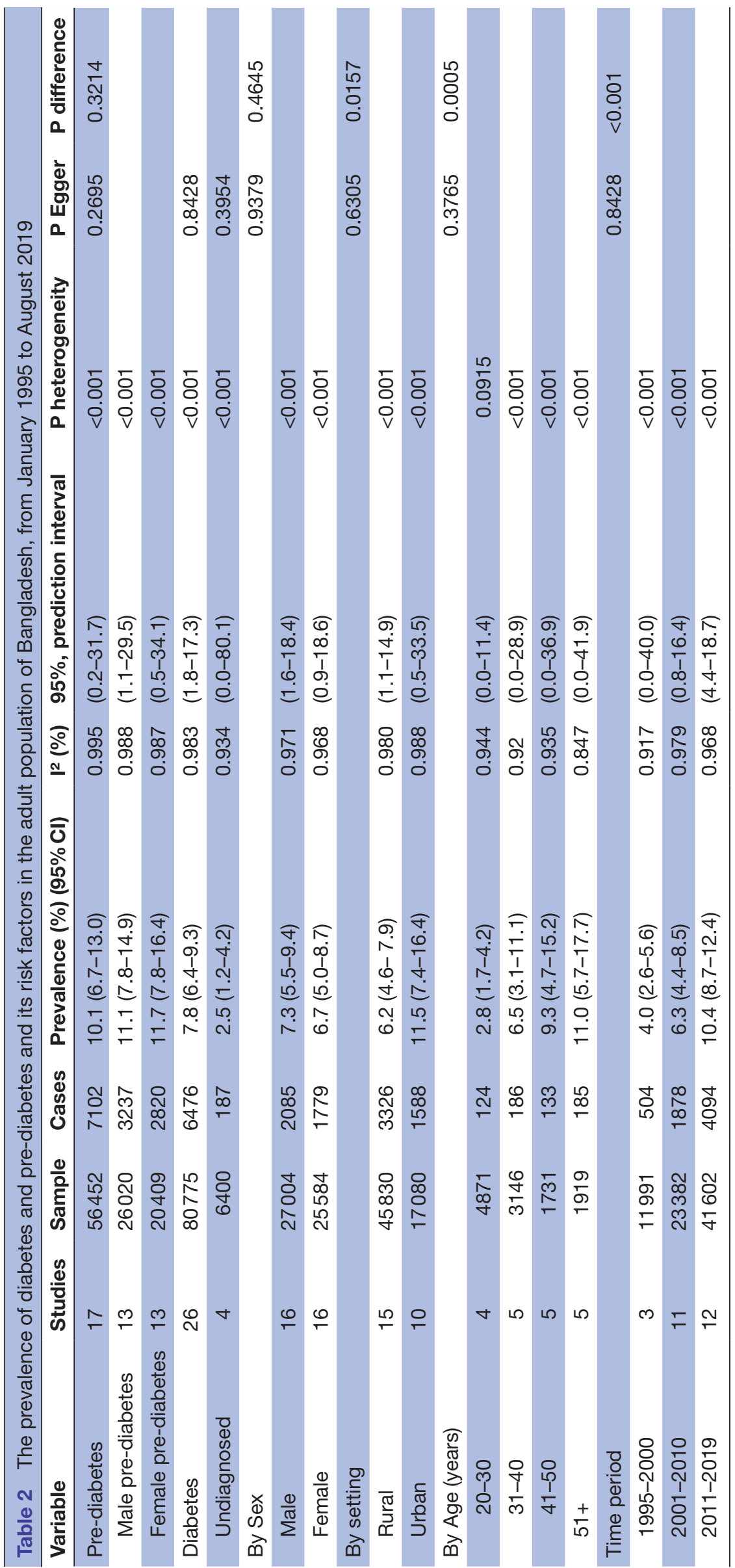




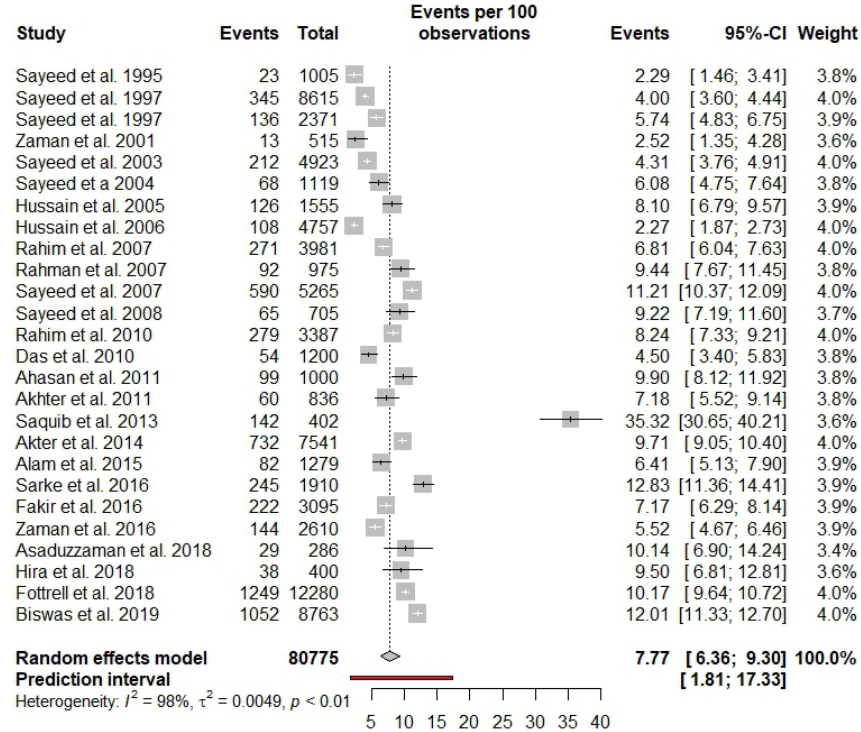

Figure 2 Forest plot of the prevalence of diabetes in the adult population of Bangladesh from January 1995 to August 2019.

The prevalence of diabetes stratified by publication periods: 1995-2000, 2001-2010 and 2011-2019. The prevalence of diabetes was $4.0 \%$ (95\% CI: 2.6-5.6), $6.3 \%$ (95\% CI: $4.4-8.5)$ and $10.4 \%$ (95\% CI: 8.7-12.4), respectively for the publication periods. For over 24 years (19952019), the pooled prevalence of diabetes has significantly increased from $4.0 \%$ to $10.4 \%$. There was no publication bias for all subgroup analyses.

The univariable meta-regression analyses (table 3) showed that the prevalence of diabetes increased with every year increase in age $(\beta=0.008 ; 95 \%$ CI: $0.003-0.012$, $\left.\mathrm{p}<0.001 ; R^{2}=26.69 \%\right)$, year of publication $(\beta=0.007$; 95\% CI: $\left.0.004-0.009, \mathrm{p}<0.0001 ; R^{2}=43.36 \%\right)$, date of data collection ( $\beta=0.008 \% ; 95 \%$ CI: $0.005-0.011, \mathrm{p}<0.0001$; $\left.R^{2}=78.58 \%\right)$ and presence of hypertension $(\beta=0.004$; 95\% CI: $0.000-0.008, \quad \mathrm{p}=0.099)$. The prevalence of diabetes was not associated with obesity or being overweight, gender, smoking status, methodological quality of articles, diagnostic method and diagnostic criteria of diabetes.

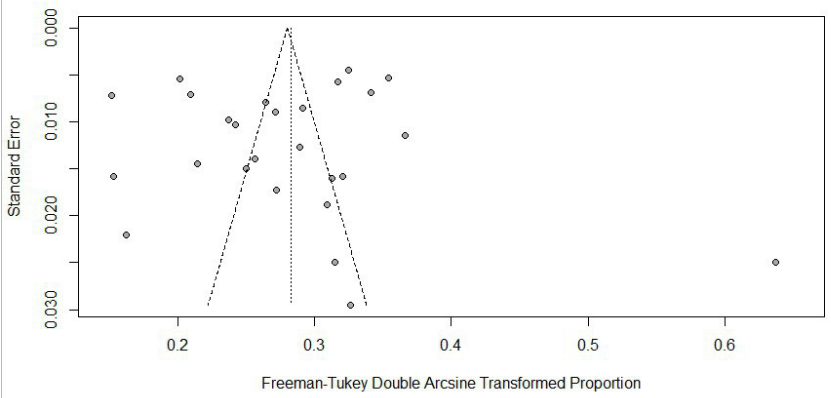

Figure 3 Funnel plot of the prevalence of diabetes in Bangladesh from January 1995 to August 2019.

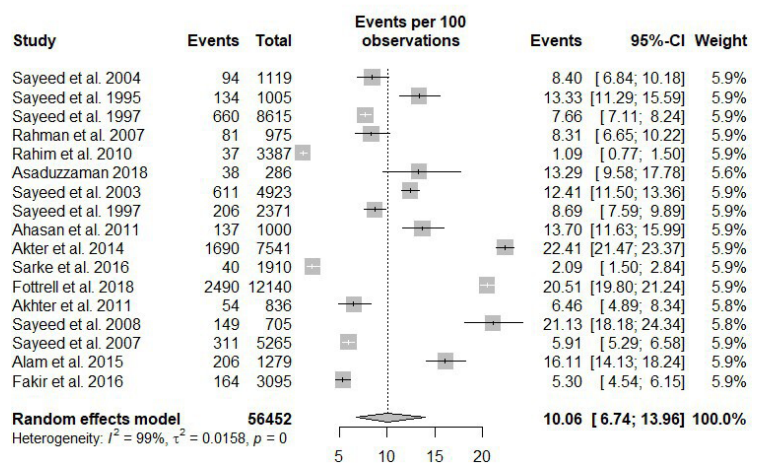

Figure 4 Forest plot of the prevalence of pre-diabetes in the adult population of Bangladesh from January 1995 to August 2019.

\section{DISCUSSION}

The main purpose of this systematic review was to compile all available data related to the prevalence of diabetes and pre-diabetes and their associated risk factors among adults in Bangladesh between 1995 and 2019. The information provided in this systematic review and metaanalysis will help to improve public health interventions to reduce the prevalence of diabetes. Twenty-six studies, based on 80775 participants, were included in this study. The results showed that the pooled prevalence of diabetes was $7.8 \%$ and the pooled prevalence of pre-diabetes was $10.1 \%$. By comparing results with other developing countries, the pooled prevalence of diabetes in Bangladesh was shown to be lower than in $\mathrm{Nepal}^{48}(8.4 \%)$ and Pakistan ${ }^{49}$ $(14.7 \%)$, while being higher than in Cameroon ${ }^{50}(5.8 \%)$ and China ${ }^{51}(6.3 \%)$. On the other hand, the pooled prevalence of pre-diabetes in Bangladesh was shown to be higher than in Cameroon ${ }^{50}(7.1 \%)$ and lower than in Pakistan $^{49}(11.43 \%)$ and Nepal ${ }^{48}(10.3 \%)$.

The pooled prevalence of pre-diabetes in Bangladesh was shown to be slightly higher than diabetes. A possible reason may be that, because the Bangladeshi labour force has been shifting away from agricultural towards manufacturing services and industry, people's energy expenditure has significantly declined. The combination of increased

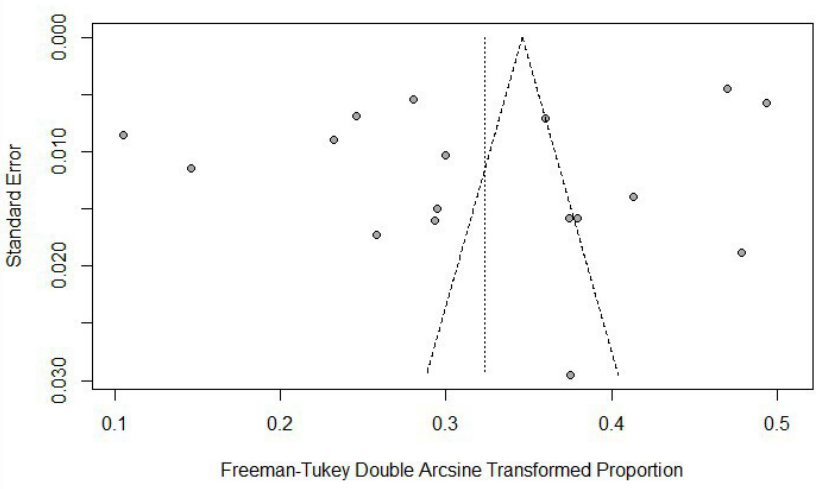

Figure 5 Funnel plot of the prevalence of pre-diabetes in Bangladesh from January 1995 to August 2019. 
Table 3 Univariate meta-regression analysis

\begin{tabular}{lcccc}
\hline Variable & Beta $(\boldsymbol{\beta})$ & $\mathbf{P}$ value & $\mathbf{9 5 \%} \mathbf{C l}$ & $\mathbf{R}^{\mathbf{2}} \mathbf{( \% )}$ \\
\hline Date of data collection & 0.008 & $<0.001$ & $0.005-0.011$ & 75.78 \\
Year of publication & 0.007 & $<0.001$ & $0.004-0.009$ & 43.36 \\
Age & 0.008 & $<0.001$ & $0.003-0.012$ & 26.69 \\
\hline Hypertension & 0.004 & 0.099 & $0.000-0.008$ & $\mathrm{Nil}$ \\
Methodology & -0.024 & 0.4121 & $-0.080-0.033$ & $\mathrm{Nil}$ \\
Overweight/obesity & 0.017 & 0.1996 & $-0.001-0.004$ & 15.14 \\
Gender & 0.001 & 0.8116 & $-0.002-0.003$ & $\mathrm{Nil}$ \\
Smoking & 0.001 & 0.9134 & $-0.012-0.010$ & $\mathrm{Nil}$ \\
Diagnostic criteria & 0.003 & 0.8786 & $-0.038-0.045$ & $\mathrm{Nil}$ \\
Diagnostic method & -0.021 & 0.2265 & $-0.055-0.013$ & 1.37 \\
\hline
\end{tabular}

energy intake and reduced energy output due to sedentary lifestyles leads to increased obesity and insulin resistance, which increases the risk of pre-diabetes.

The prevalence of diabetes according to this study is consistent with an earlier scoping review. ${ }^{52}$ Urbanisation is ongoing in Bangladesh and has increased from $28.97 \%$ in 2008 to $36.63 \%$ in 2018. The pooled prevalence of diabetes in urban populations $(11.5 \%)$ is significantly higher than rural populations $(6.2 \%)$. A higher prevalence of diabetes in urban than rural areas is reported in most countries across the world ${ }^{53}$ Urbanisation is related to changes in eating habits, physical activity and exercise, smoking and alcohol consumption, which are risks factors for obesity and diabetes. ${ }^{54}$ Our results also demonstrated that the pooled prevalence of diabetes was slightly higher among men than among women $(7.34 \%$ compared with $6.70 \%)$. This result is consistent with previous literature. ${ }^{55}$ On the other hand, there was no significant difference in the pooled prevalence of pre-diabetes between men and women. The prevalence of diabetes has increased 2.5 times over the last two decades from $4.0 \%$ in $1995-2000$ to $10.4 \%$ in $2010-2019$.

The systematic review and meta-analysis has several strengths as well as a few limitations. We used a comprehensive search strategy to identify all eligible studies and attempted to increase the quality and comparability of the included studies by using well-defined eligibility criteria. No publication bias was found in our analysis which demonstrates that we did not miss any potential studies that could have change the findings of this metaanalysis. Moreover, all included studies had a low risk of bias in their methodological quality. As shown by the meta-regression analyses, the overall methodological quality of the studies had an insignificant impact on the overall prevalence estimate. Furthermore, the included articles in this study cover all divisions of Bangladesh.

Our study has some potential limitations: First, a high heterogeneity was found between the included studies. However, we used subgroup analyses and meta-regression to cover the potential heterogeneity by adding covariates (ie, publication year, geographical area, sample size, proportion of male participants and study quality) to the bivariate model. Therefore, the estimates of this study should be interpreted with caution. Second, in this systematic review, we were unable to differentiate between the type 1 and type 2 diabetes; nonetheless, evidence shows that type 2 diabetes accounts for $90 \%-95 \%$ of all diabetes cases. ${ }^{47}$ Third, we only considered univariable meta-regression analysis to test the significance of each covariate instead of multivariable meta-regression analyses. Multivariable meta-regression analyses might be a useful technique to take into account the variance due to diagnostic criteria for diabetes. However, the univariate analysis showed that the $\mathrm{p}$ values for both diagnostic method and diagnostic criteria are very high (method: $\mathrm{p}=22.65$ and criteria: $\mathrm{p}=87.86$ ). A variable with a high $\mathrm{p}$ value from univariate analysis is usually dropped out from the multivariable analysis. This is because of when the other variables in the model are adjusted for it, their effects remain almost the same as of their unadjusted effects. Furthermore, a limited number of studies in this review is also another potential barrier of performing multivariable meta-regression analysis.

Finally, being obese or overweight was found to be a statistically insignificant covariate of diabetes. This may be due to the limited number of studies in this systematic review and meta-analysis.

\section{CONCLUSION}

This systematic review and meta-analysis provides a comprehensive overview on the prevalence of diabetes and pre-diabetes in Bangladesh. In the absence of a national diabetes registry, the findings of this review provide an estimate of the prevalence of diabetes and pre-diabetes among the adult population in Bangladesh. Because of the high prevalence, we believe that a comprehensive national diabetes register is urgently needed in Bangladesh. Findings from this review revealed that the main drivers of diabetes are increased age, hypertension, urbanisation and time period. 
As the prevalence of diabetes and pre-diabetes in Bangladesh is on the rise, the Bangladeshi government should set up diabetes control programmes all over the country. A policy intervention is a need of time to reduce the prevalence of diabetes in Bangladesh. In addition, Bangladeshi people should retain their traditional and more active lifestyles, which should include more physical activities and healthy food.

Contributors $\mathrm{SA}, \mathrm{JAN}, \mathrm{AS}$ and MAS conceived, designed and wrote the manuscript. $A S, B B, A J, R M, N N$ and MAS conducted the data collection analysis and edited the manuscript. SA, AJ, NN, JAN, RM and BB reviewed and gave the final approval for the manuscript. All authors read and approved the final manuscript.

Funding The authors have not declared a specific grant for this research from any funding agency in the public, commercial or not-for-profit sectors.

Competing interests None declared.

Patient consent for publication Not required.

Provenance and peer review Not commissioned; externally peer reviewed.

Data availability statement Data are available in a public, open access repository. All data relevant to the study are included in the article or uploaded as supplementary information. All data are inside the paper.

Open access This is an open access article distributed in accordance with the Creative Commons Attribution Non Commercial (CC BY-NC 4.0) license, which permits others to distribute, remix, adapt, build upon this work non-commercially, and license their derivative works on different terms, provided the original work is properly cited, appropriate credit is given, any changes made indicated, and the use is non-commercial. See: http://creativecommons.org/licenses/by-nc/4.0/.

ORCID iD

Sohail Akhtar http://orcid.org/0000-0001-8293-6328

\section{REFERENCES}

1 Zimmet PZ, Magliano DJ, Herman WH, et al. Diabetes: a 21st century challenge. Lancet Diabetes Endocrinol 2014;2:56-64.

2 Atlas, Diabetes. International diabetes Federation. 10th edi. IDF diabetes Atlas, 2019.

3 Guariguata L, Whiting DR, Hambleton I, et al. Global estimates of diabetes prevalence for 2013 and projections for 2035. Diabetes Res Clin Pract 2014;103:137-49.

4 Ramachandran A, Snehalatha C, Ma RCW. Diabetes in south-east Asia: an update. Diabetes Res Clin Pract 2014;103:231-7.

5 Chowdhury MZI, Anik AM, Farhana Z, et al. Prevalence of metabolic syndrome in Bangladesh: a systematic review and meta-analysis of the studies. BMC Public Health 2018;18:308.

6 Jayawardena R, Ranasinghe P, Byrne NM, et al. Prevalence and trends of the diabetes epidemic in South Asia: a systematic review and meta-analysis. BMC Public Health 2012;12:380.

7 Shaw JE, Sicree RA, Zimmet PZ. Global estimates of the prevalence of diabetes for 2010 and 2030. Diabetes Res Clin Pract 2010;87:4-14.

8 Baral S, Uprety S, Lamichhane B. Backgroun of diabetes. Available: https://www.herd.org.np /uploads/frontend/Publications/ PublicationsAttachments1/1480578900-Backgrounder\%20on\% 20DIABETES.pdf [Accessed 06 Sep 2019].

9 Hu FB. Globalization of diabetes: the role of diet, lifestyle, and genes. Diabetes Care 2011;34:1249-57.

10 International centre for diarrhoeal disease research Bangladesh. Available: https://www.icddrb.org/news-and-events/press-corner/ media-resources/non-communicable-diseases [Accessed 06 Sep 2019].

11 Abu Sayeed M, Banu A, Khan AR, et al. Prevalence of diabetes and hypertension in a rural population of Bangladesh. Diabetes Care 1995;18:555-8.

12 Saquib N, Khanam MA, Saquib J, et al. High prevalence of type 2 diabetes among the urban middle class in Bangladesh. BMC Public Health 2013;13:1032.

13 Saquib N, Saquib J, Ahmed T, et al. Cardiovascular diseases and type 2 diabetes in Bangladesh: a systematic review and metaanalysis of studies between 1995 and 2010. BMC Public Health 2012;12:434.
14 Moher D, Liberati A, Tetzlaff J, et al. Preferred reporting items for systematic reviews and meta-analyses: the PRISMA statement. PLoS Med 2009;6:e1000097.

15 National Heart, Lung and Blood Institute. Quality assessment tool for observational cohort and cross-sectional studies. available online. Available: https://www.nhlbi.nih.gov/health-topics/study-qualityassessment-tools [Accessed 1 Oct 2019].

16 Fleiss JL. The statistical basis of meta-analysis. Stat Methods Med Res 1993;2:121-45.

17 Brockwell SE, Gordon IR. A comparison of statistical methods for meta-analysis. Stat Med 2001;20:825-40.

18 Chen $\mathrm{H}$, Manning AK, Dupuis J. A method of moments estimator for random effect multivariate meta-analysis. Biometrics 2012;68:1278-84.

19 Kontopantelis E, Reeves D. Performance of statistical methods for meta-analysis when true study effects are non-normally distributed: a comparison between DerSimonian-Laird and restricted maximum likelihood. Stat Methods Med Res 2012;21:657-9.

20 Guyatt GH, Oxman AD, Kunz R, et al. GRADE guidelines 6. Rating the quality of evidence--imprecision. J Clin Epidemiol 2011;64:1283-93.

21 Egger M, Davey Smith G, Schneider M, et al. Bias in meta-analysis detected by a simple, graphical test. BMJ 1997;315:629-34.

22 Higgins JPT, Thompson SG. Quantifying heterogeneity in a metaanalysis. Stat Med 2002;21:1539-58.

23 Viera AJ, Garrett JM. Understanding interobserver agreement: the kappa statistic. Fam Med 2005;37:360-3.

24 Sayeed MA, Hussain MZ, Banu A, et al. Prevalence of diabetes in a suburban population of Bangladesh. Diabetes Res Clin Pract 1997;34:149-55.

25 abu Sayeed M, Ali L, Hussain MZ, et al. Effect of socioeconomic risk factors on the difference in prevalence of diabetes between rural and urban populations in Bangladesh. Diabetes Care 1997;20:551-5.

26 Zaman MM, Yoshiike N, Rouf MA, et al. Cardiovascular risk factors: distribution and prevalence in a rural population of Bangladesh. $J$ Cardiovasc Risk 2001;8:103-8.

27 Sayeed MA, Mahtab H, Akter Khanam P, et al. Diabetes and impaired fasting glycemia in a rural population of Bangladesh. Diabetes Care 2003:26:1034-9.

28 Abu Sayeed M, Mahtab H, Akter Khanam P, et al. Diabetes and impaired fasting glycemia in the tribes of Khagrachari Hill tracts of Bangladesh. Diabetes Care 2004;27:1054-9.

29 Hussain A, Rahim MA, Azad Khan AK, et al. Type 2 diabetes in rural and urban population: diverse prevalence and associated risk factors in Bangladesh. Diabet Med 2005;22:931-6.

30 Hussain A, Vaaler S, Sayeed MA, et al. Type 2 diabetes and impaired fasting blood glucose in rural Bangladesh: a population-based study. Eur J Public Health 2007;17:291-6.

31 Rahim MA, Hussain A, Azad Khan AK, et al. Rising prevalence of type 2 diabetes in rural Bangladesh: a population based study. Diabetes Res Clin Pract 2007;77:300-5.

32 Rahman MM, Rahim MA, Nahar Q. Prevalence and risk factors of type 2 diabetes in an urbanizing rural community of Bangladesh. Bangladesh Med Res Counc Bull 2007;33:48-54.

33 Sayeed MA, Mahtab H, Khanam PA, et al. Prevalence of diabetes and impaired fasting glucose in urban population of Bangladesh. Bangladesh Med Res Counc Bull 2007;33:1-2.

34 Sayeed S, Banu A, Khanam PA, et al. Prevalence of metabolic syndrom in three urban communities of Dhaka City. Ibrahim Med Coll J 2008;2:44-8.

35 Rahim MA, Azad Khan AK, Nahar Q, et al. Impaired fasting glucose and impaired glucose tolerance in rural population of Bangladesh. Bangladesh Med Res Counc Bull 2010;36:47-51.

36 Das S, Dutta PK. Chronic kidney disease prevalence among health care providers in Bangladesh. Mymensingh Med J 2010;19:415-21.

37 Ahasan HAMN, Islam MDZ, Alam MDB, et al. Prevalence and risk factors of type 2 diabetes mellitus among Secretariat employees of Bangladesh. J Med 2011;12:125-30.

38 Akhter A, Fatema K, Afroz A. Prevalence of diabetes mellitus and its associated risk indicators in a rural Bangladeshi population. Open Diabetes J 2011;4:6-13.

39 Akter S, Rahman MM, Abe SK, et al. Prevalence of diabetes and prediabetes and their risk factors among Bangladeshi adults: a nationwide survey. Bull World Health Organ 2014;92:204-13.

40 Islam FMA, Chakrabarti R, Islam MT, et al. Prediabetes, diagnosed and undiagnosed diabetes, their risk factors and association with knowledge of diabetes in rural Bangladesh: the Bangladesh population-based diabetes and eye study. J Diabetes 2016;8:260-8.

41 Alam DS, Talukder SH, Chowdhury MAH, et al. Overweight and abdominal obesity as determinants of undiagnosed diabetes and pre-diabetes in Bangladesh. BMC Obes 2016;3:19. 
42 Sarker M, Barua M, Guerra F, et al. Double trouble: prevalence and factors associated with tuberculosis and diabetes comorbidity in Bangladesh. PLoS One 2011;11:e0165396.

43 Zaman MM, Rahman MM, Rahman MR, et al. Prevalence of risk factors for non-communicable diseases in Bangladesh: results from steps survey 2010. Indian J Public Health 2016;60:17-25.

44 Asaduzzaman M, Chowdhury S, Shahed JH, et al. Prevalence of type 2 diabetes mellitus among urban Bihari communities in Dhaka, Bangladesh: a cross-sectional study in a minor ethnic group. Cureus 2018;10.

45 Hira R, Miah MAW, Akash DH. Prevalence of Type 2 Diabetes Mellitus in Rural Adults (>_31years) in Bangladesh. Faridpur Medical College Journal 2018;13:20-3.

46 Fottrell E, Ahmed N, Shaha SK, et al. Distribution of diabetes, hypertension and non-communicable disease risk factors among adults in rural Bangladesh: a cross-sectional survey. BMJ Glob Health 2018;3:e000787.

47 Biswas T, Townsend N, Islam MS, et al. Association between socioeconomic status and prevalence of non-communicable diseases risk factors and comorbidities in Bangladesh: findings from a nationwide cross-sectional survey. BMJ Open 2019;9:e025538.
48 Gyawali B, Sharma R, Neupane D, et al. Prevalence of type 2 diabetes in Nepal: a systematic review and meta-analysis from 2000 to 2014. Glob Health Action 2015;8:29088.

49 Akhtar S, Nasir JA, Abbas T, et al. Diabetes in Pakistan: a systematic review and meta-analysis. Pak J Med Sci 2019;35:1173.

50 Bigna JJ, Nansseu JR, Katte J-C, et al. Prevalence of prediabetes and diabetes mellitus among adults residing in Cameroon: a systematic review and meta-analysis. Diabetes Res Clin Pract 2018;137:109-18.

51 Zhang DD, Tang X, Jin DY, et al. [Prevalence of diabetes in Chinese adults: a Meta-analysis]. Zhonghua Liu Xing Bing Xue Za Zhi 2018;39:852-7.

52 Biswas T, Islam A, Rawal LB, et al. Increasing prevalence of diabetes in Bangladesh: a scoping review. Public Health 2016;138:4-11.

53 International Diabetes Federation. IDF diabetes atlas. 8th edn, 2017.

54 Allender S, Lacey B, Webster P, et al. Level of urbanization and noncommunicable disease risk factors in Tamil Nadu, India. Bull World Health Organ 2010;88:297-304.

55 American Diabetes Association. Diagnosis and classification of diabetes mellitus. Diabetes Care 2010;33 Suppl 1:S62-9. 